\title{
FEATURES OF BLOOD SUPPLY AND INNERVATION OF THE SHOULDER GIRDLE MUSCLES IN HUMAN FETUSES
}

\author{
Tatiana V. KHMARA ${ }^{1 凶}$, Hrystyna Z. SHEVCHUK ${ }^{1}$, Svetlana D. NOVYCHENKOㄹ, \\ Anna I. ANDRUSHAK ${ }^{1}$ \\ ${ }^{1}$ Higher State Educational Institution of Ukraine „Bukovinian State Medical University“, Chernivtsi, \\ Ukraine
}

\author{
Received 17 Aug 2019, Accepted 09 Oct 2019 \\ hitps://doi.org/10.31688/ABMU.2019.54.4.03
}

\begin{abstract}
Introduction. The brachial plexus injury represents $3-5 \%$ of all injuries and is considered to be one of the most serious types of injuries to the musculoskeletal system, due to the development of severe and often irreversible changes.
\end{abstract}

The objective of the study was to establish the features of blood supply and innervation of the shoulder girdle muscles in 4-10-month-old human fetuses.

Materials and methods. Using methods of macromicroscopic preparation, vascular injection and morphometry, the fetal topography of the arteries and nerves of the shoulder girdle muscles was studied in 37 human fetuses, 4-10-month-old.

Results. The quadrangular space in the experimental fetuses is a narrow axillary canal in which three permanent walls, anterior and posterior foramina can be distinguished. The surgical neck of the humerus is the fourth non-permanent wall of the axillary canal. At the same time, the branching of the axillary nerve into secondary trunks for the most part occurs before entering the canal or in the canal itself. The triangular space looks like an axillary fissure. It has been established that the nature of the intramuscular distribution of blood vessels and nerves in each muscle of the shoulder girdle is peculiar and differs

\section{Résumé}

Caractéristiques d'irrigation sanguine et d'innervation des muscles de la ceinture scapulaire chez les foetus humains

Introduction. La lésion du plexus brachial représente 3 à $5 \%$ du total des lésions et est considérée d'être l'une des plus graves lésions du système musculo-squelettique à cause de l'évolution de modifications sévères et souvent irréversibles.

Le but de l'étude. Établir les caractéristiques d'irrigation sanguine et de l'innervation des muscles de la ceinture scapulaire chez les foetus humains de 4 à 10 mois.

Matériaux et méthodes. En utilisant les méthodes de préparation macromicroscopique, d'injection vasculaire et de morphométrie, la topographie foetale des artères et des nerfs des muscles de la ceinture scapulaire a été étudiée chez 37 foetus humains âgés de 4 à 10 mois.

Résultats. Chez les foetus étudiés, l'ouverture quadrilatérale est un canal axillaire étroit dans lequel se distinguent trois parois permanentes, les ouvertures antérieure et postérieure. Le quatrième paroi non permanente du canal axillaire est le col chirurgical de l'humérus. En même temps, la division du nerf 
in the topography of muscle fiber bundles. In all the muscles of the shoulder girdle, intra-and intramuscular anastomoses between arteries of different orders and diameters were clearly detected.

Conclusions. The axillary nerve is involved in the innervation of the posterior artery, enveloping the humerus and of its branches. In each muscle, one can meet both a loose and a main pattern of branching of the arteries regardless of their shape. When the direction of the vessels and muscle bundles is in line, the main form of branching (infraspinous and subscapularis muscles) is usually formed, and if they do not conform, it is mainly loose (deltoid, supraspinous, teres minor and major muscles).

Keywords: muscle, shoulder girdle, blood supply, innervation, fetus, human. axillaire en troncs secondaires se produit en grande partie avant d'entrer dans le canal ou dans le canal lui-même. L'ouverture trilatérale a une fente axillaire. Il a été établi que la distribution intramusculaire des vaisseaux sanguins et des nerfs dans chaque muscle de la ceinture scapulaire est particulière et diffère par la topographie des faisceaux de fibres musculaires. Des anastomoses extra et intramusculaires entre des artères d'ordres et de diamètres différents ont été clairement détectées dans tous les muscles de la ceinture scapulaire.

Conclusions. Le nerf axillaire est impliqué dans l'innervation de l'artère postérieure, enveloppant l'humérus et ses branches. Dans chaque muscle, on peut rencontrer un type de ramification des artères lâche et principale, quelle que soit leur forme. Lorsque la direction des vaisseaux et des faisceaux musculaires est alignée, il se forme généralement une forme de ramification du tronc (muscles infra-épineux et subscapulaire) et en cas d'incohérence, elle est principalement lâche (deltoïde, muscles petit et grand ronds).

Mots-clés: muscle, ceinture scapulaire, irrigation sanguine, innervation, fœetus, homme.

electroneuromyography of the supraspinous and infraspinous muscles (in order to assess the state of the muscles responsible for the external rotation of the shoulder) and cutaneous electroneuromyography of the biceps (flexion of the arm at the elbow).

The studies of recent years have evaluated the surgical anatomy of all muscles suitable for transpositions in detail: the broadest muscle, the greater pectoral muscle, the triceps muscle of the shoulder, the trapezius muscle ${ }^{13}$. In these papers, a purposeful tendency of using these muscles to restore flexion in the elbow joint is well traced. At the same time, the abduction in the shoulder joint and its rotational movements are partially restored as a result of the operations performed.

Orthopedists and traumatologists draw a special attention to the revision of views on the mechanism of movements in the shoulder joint. If earlier the deltoid muscle was considered to be the main mover of the shoulder, now it has been proved that the muscles that form the rotator cuff are the very mechanism without which the arm has no chance of physical activity ${ }^{1}$. Rotatory cuff of consists of four muscles: supraspinous, subscapular, infraspinatus and teres minor muscles. The supraspinous muscle is the most important for the shoulder joint functionally. Due to the balance of these muscles, the humeral head is stabilized and centered in the glenoid cavity and rotates evenly in it. 
Special papers on the typical and variant anatomy of the blood supply to the muscles of the shoulder girdle ${ }^{14-17}$ mainly only cover the extraorganic part of the bloodstream, without addressing the issue of intramuscular branching of the vessels, vascularization features of various muscle segments and vascular bed topography. The literature available to us contains isolated information on the anatomical variability of the nerves of the brachial plexus and the branches of the subclavian and axillary arteries, which take part in innervation and blood supply of the muscles of the shoulder girdle respectively ${ }^{18-22}$

The development of fetal surgery requires anatomists to comprehensively research options for the topography of the vessels and nerves of the upper limb in the fetal period of human ontogenesis. Expansion of indications for surgical interventions on muscles and neurovascular structures of the deltoid, scapular, axillary areas necessitates the purposeful study of their topographic-anatomical features in human fetuses. Literature sources do not contain data on intramuscular branching of nerves and arteries in the muscles of the shoulder girdle in human fetuses.

\section{THE OBJeCtive OF THE STUDY}

Based on the above, we set a goal to establish the characteristics of the blood supply and innervation of the shoulder girdle muscles in 4-10-month-old human fetuses.

\section{Materials AND Methods}

A macroscopic study was carried out on specimens of the upper extremities of 37 human fetuses with $81.0-375.0 \mathrm{~mm}$ of the crown-rump length (CRL), using the methods of macromicroscopic preparation, vascular injection and morphometry. We studied the topography of the nerves and main vascular ways, the number of feed sources heading to the individual muscles of the shoulder girdle, the number, angle of branching and entry of the muscle branches, the presence of intramuscular anastomoses.

\section{Results AND discussion}

It has been established that the main source of blood supply to the supraspinous muscle is the suprascapular artery, which branches out within the upper third of the costal and posterior surfaces of the scapula, moreover there are more of them on the back of the scapula than on the anterior side. It should be noted that in the region of the medial edge of the scapula, the $1-2$ branches of the suprascapular artery anastomose with the branches of the transverse artery of the neck. In 48 (64.9\%) cases, the trunk of the suprascapular artery was relatively long and reached the infraspinous fossa. When the main trunk of the suprascapular artery was short (26 cases - 35.1\%), it ended within the supraspinous fossa, and a thin connecting branch entered the infraspinous fossa and anastomosed with the artery around the scapula. The latter, accompanied by a vein of the same name, passes through the medial triangle axillary fissure - a triangular space that is limited: superiorly - by the teres minor muscle and the lower edge of the subscapular muscle, inferiorly - by the teres major muscle and laterally by the long head of the triceps.

The suprascapular nerve passes through the scapular notch into the supraspinous fossa and is located under the supraspinous muscle, perpendicular to the course of its bundles. Then, the suprascapular nerve passes under the inferior transverse ligament of the scapula and reaches the infraspinous fossa, branching out into the infraspinous muscle. The latter is mainly supplied with blood by the branches of the artery that surrounds the scapula, which anastomose with the branches of the suprascapular artery, the transverse artery of the neck and the posterior artery, which surrounds the humerus (Fig. 1). In 52 (70.3\%) observations we found the loose type of branching of the artery around the scapula. In this case, as a rule, 3-4 branches from the artery, enveloping the scapula head to the costal surface of the scapula and $1-2$ branches - to its rear surface. Thus, the number of branches of the artery enveloping the scapula is 2 times greater on the costal surface of the scapula than on the back.

The deltoid muscle is supplied by the thoracoacromial artery and the posterior artery enveloping the humerus. Within the quadrangular space 1-3 branches heading to the posterior sections of the deltoid muscle branch out from the posterior artery which envelopes the humerus (Fig. 2). The axillary nerve arises through the quadrangular space under the deltoid muscle, along with the posterior artery and vein, enveloping the humerus. Studying the anatomy of the axillary nerve branches, we came across a few specimens in which the axillary area vessels were innervated by the axillary nerve. A characteristic feature of all (13) of these cases was that the vascular branch of the axillary nerve was always woven into the adventitia in the angle formed by the axillary artery and the posterior artery, enveloping the humerus, or at least penetrated the latter near its branching from the axillary artery and further extended to its branches. The second feature of our experimental specimens was that in 8 cases out of 13 , the vascular branches were small branches of the main branch, which innervates the shoulder joint capsule. Then, it should 


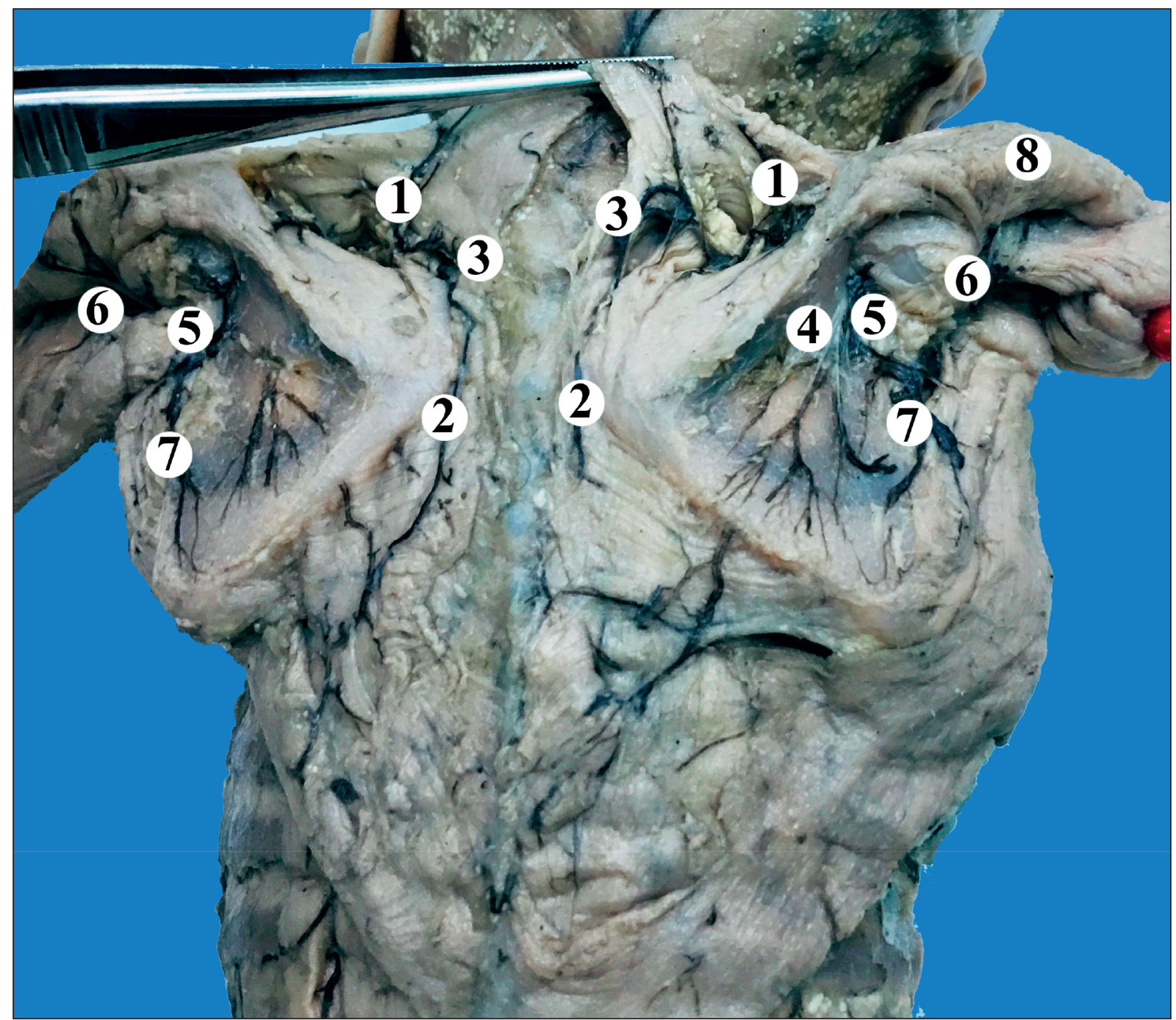

Fig. 1. Blood supply and innervation of the shoulder girdle muscles of a fetus with $130.0 \mathrm{~mm}$ of CRL (supraspinous and deltoid muscles are drawn upwards). Gross specimen.

1 - suprascapular artery; 2 - transverse artery of neck; 3 - anastomosis between the suprascapular artery and the transverse artery of neck; 4 - suprascapular nerve; 5 - artery and vein enveloping the scapula; 6 - posterior artery and vein, enveloping humerus; 7 - thoracoacromial artery and vein; 8 - axillary nerve.

be noted that in 5 cases the axillary nerve innervated not the trunk of the posterior artery, enveloping the humerus, but those of its branches that supply the shoulder joint capsule.

It should be noted that the quadrangular space in the experimental human fetuses was a narrow axillary canal in which the walls as well as the front and rear foramina can be distinguished. The front foramen of the canal is limited by the long head of the triceps, the outer edge of the subscapular muscle and the inner edge of the tendon of the broadest muscle of back. Thus, the front foramen of the canal has three borders. It should be emphasized that the surgical neck of the humerus does not directly participate in the formation of the borders of the anterior foramen of the canal.
One can find three permanent walls of the axillary canal in fetuses: external, inferior and medial ones. The inner edge of the teres major muscle is the external wall of the canal while the lower wall was formed by the upper surface of the long head of the triceps and the medial wall, which in the anteroposterior direction consists of the following elements: the outer edge of the subscapular muscle, the free area of the shoulder joint capsule, the outer edge of the teres minor muscle. It should be noted that a relatively small area of the shoulder joint capsule, not protected by muscles, the free area of the shoulder joint capsule is limited: anteriorly by the subscapular muscle, posteriorly by the teres minor muscle, superiorly by the line of attachment of the joint capsule to the anatomical 


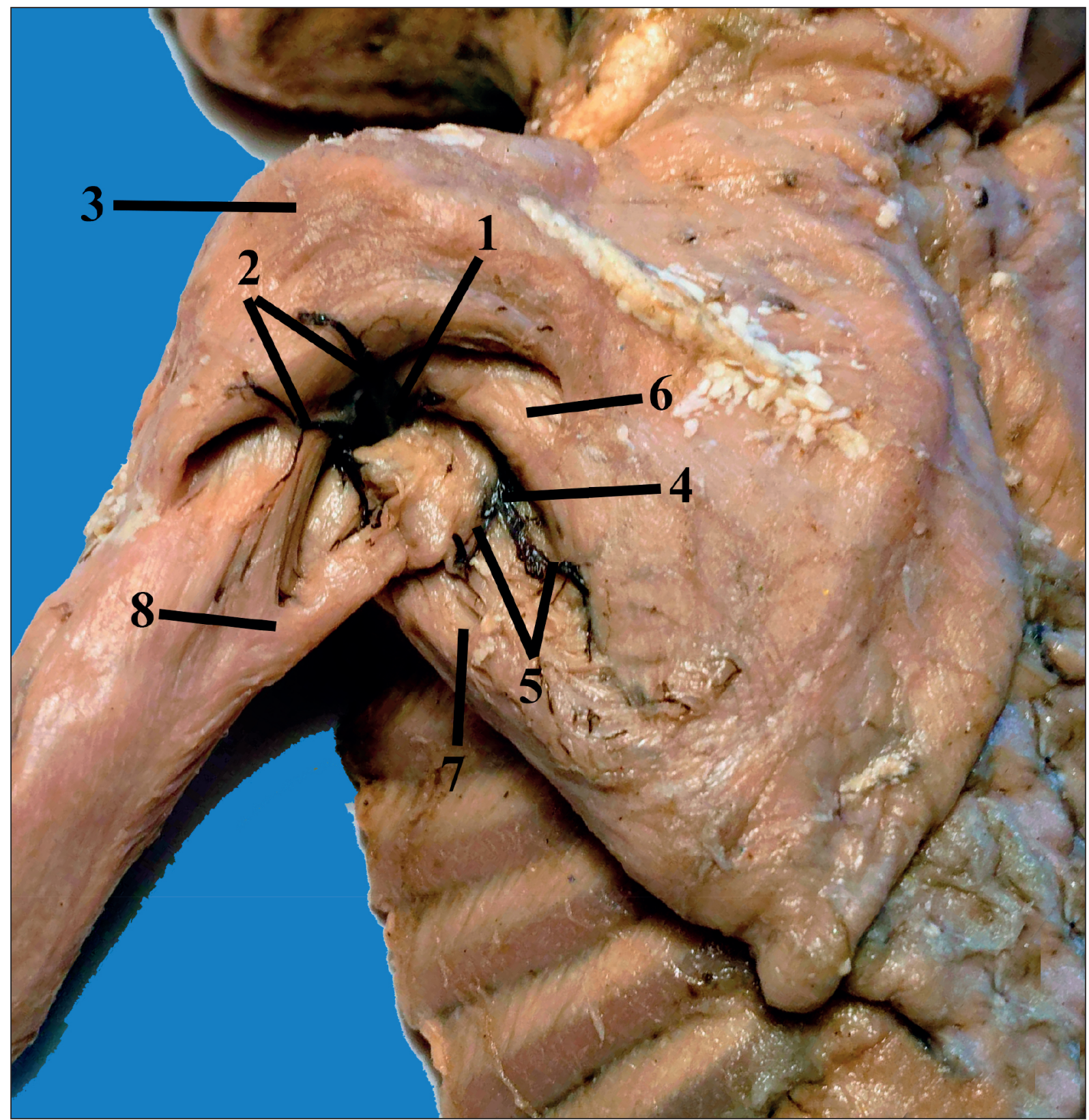

Fig. 2. The structures of the posterior wall of the left axillary cavity in a fetus with $160,0 \mathrm{~mm}$ CRL. Gross specimen.

1 - quadrangular space (axillary canal); 2 - posterior artery and vein, enveloping the humerus; 3 - deltoid muscle; 4 - triangular space (axillary fossa); 5 - artery and vein, enveloping the scapula; 6 - teres minor muscle; 7 - teres major muscle; 8 - the long head of the shoulder triceps .

neck of the humerus and inferiorly by the long head of the triceps. The section of the free part of the shoulder joint capsule has a shape close to the trapezoid one, whose upper border its broad base, and the lower one is its narrow base. The fourth upper wall of the axillary canal, formed by the neck of the humerus, is not permanent. We observed it on 11 specimens ( $14.9 \%$ of cases) when some distance remained between the attachment of the teres major muscle and the shoulder joint capsule to the humerus. In the remaining specimens, the teres major muscle was attached to the shoulder joint capsule so close that it was not necessary to mention the upper wall of the canal.

The posterior foramen of the canal has four borders formed by the inner edge of the teres major muscle, the outer edge of the teres minor muscle, the upper surface of the long head of the shoulder triceps, and the surgical neck of the humerus covered with soft tissues.

The axillary canal in fetuses aged 4-6 months is $4.8 \pm 0.4 \mathrm{~mm}$ long, in fetuses aged $7-8$ months $8.7 \pm 0.6$ 


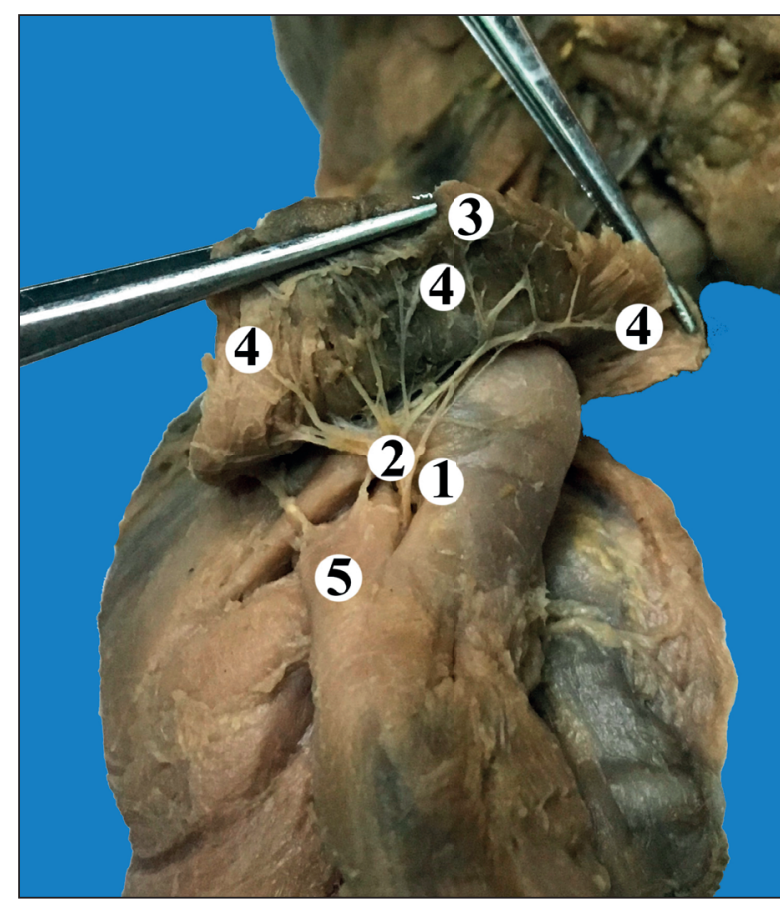

Fig. 3. Branching of the right axillary nerve in the deltoid muscle of a fetus with $175.0 \mathrm{~mm}$ of CRL. Gross specimen.

1 - quadrangular space (axillary canal); 2 - axillary nerve trunk; 3 - deltoid muscle (drawn up); 4 - axillary nerve branches; 5 - the long head of the shoulder triceps.

$\mathrm{mm}$ and in fetuses aged $9-10$ months $13.8 \pm 2.3 \mathrm{~mm}$ long.

Taking into account the topography of the axillary nerve, we have identified three nerve segments: 1) before entering the canal; 2) in the canal; 3) after leaving the canal. To determine the level of axillary nerve origin from the brachial plexus, we took the outer edge of the subscapular muscle as a reference point.

According to our findings, in fetuses aged 4-6 months, the level of axillary nerve origin is $4.8 \pm 0.7$ $\mathrm{mm}$ from the outer edge of the subscapular muscle and medially from it, and in fetuses aged 9-10 months at a distance of $9.3 \pm 0,6 \mathrm{~mm}$ respectively. The length of the axillary nerve to the origin of its first branch is from $4.0 \pm 0.3 \mathrm{~mm}$ (in fetuses aged 4 months) to $7.2 \pm 0.5 \mathrm{~mm}$ (in fetuses aged 10 months). In the axillary canal the nerve consistently adheres to all elements of the medial wall of the canal. The division of the axillary nerve into its secondary trunks can occur at different levels. Predominantly (39.2\%), the axillary nerve was divided at the level of the outer edge of the subscapular muscle, in the canal itself $(36.5 \%)$ or on leaving the canal (17.6\%). In 5 cases (6.7\%) we observed that the axillary nerve was also divided on the anterior surface of the subscapular muscle. Thus, only in $17.6 \%$ of cases the trunk of the axillary nerve passed through the canal (Fig. 3), in other cases its secondary trunks did.

As a rule, the secondary trunks of the axillary nerve or just the trunk of the nerve, or, more rarely, the trunk of the axillary nerve and its secondary trunks, adjoin the free section of the shoulder joint capsule as an element of the medial wall of the axillary canal.

Before entering the canal or in the canal itself 1-3 muscle branches that head to the posterior sections of the deltoid muscle, parallel to the course of its muscle fibers, leave the axillary nerve. At the level of the posterior edge of the deltoid muscle, one skin branch usually leaves the axillary nerve. It should be noted that on the anterior surface of the surgical neck of the humerus, the axillary nerve trunk is divided into 2-4 terminal branches, of which 1-3 are muscular and one branch is articular (Fig. 4). Muscular (1-2) branches of the axillary nerve also provide the innervation of the teres minor muscle. The teres minor muscle, as a rule, is supplied by one, less often 2 branches from the artery, enveloping the scapula, posterior and anterior arteries, enveloping the humerus, the transverse artery of neck, which also anastomose among themselves.

4-7 branches from the artery enveloping the scapula head to the anterior surface of the subscapular muscle. 2-3 branches of the suprascapular artery anastomose with the letter and the transverse artery of the neck. 1-2 branches that anastomose with the branches of the suprascapular artery, as well as the artery enveloping the scapula and the transverse artery of the neck branch out from the subscapular artery to the muscle of the same name. It should be emphasized that $1-3$ branches of the thoracoacromial artery anastomose with the transverse artery of the neck and the artery enveloping the scapula. 1-2 branches from the anterior and posterior arteries, enveloping the humerus anastomose between themselves, as well as with the suprascapular and subscapular arteries. The posterior surface of the subscapular muscle is supplied by 2-4 branches of the artery enveloping the scapula, which anastomose with the branches of the suprascapular artery, which goes caudally from the supraspinous fossa into the subscapular fossa along the posterior surface of the scapula. In 56 (75.7\%) cases, an anastomosis was found in the region of the supra- and infraspinous fossae.

The subscapular nerve in the region of the lateral angle of the scapula penetrates into the subscapular fossa, with $2-3$ branches descending along the anterior surface of the muscle of the same name, innervating it and the teres major muscle (Fig. 5). The latter is mainly supplied with blood by the subscapular artery. The teres major muscle is also supplied by 


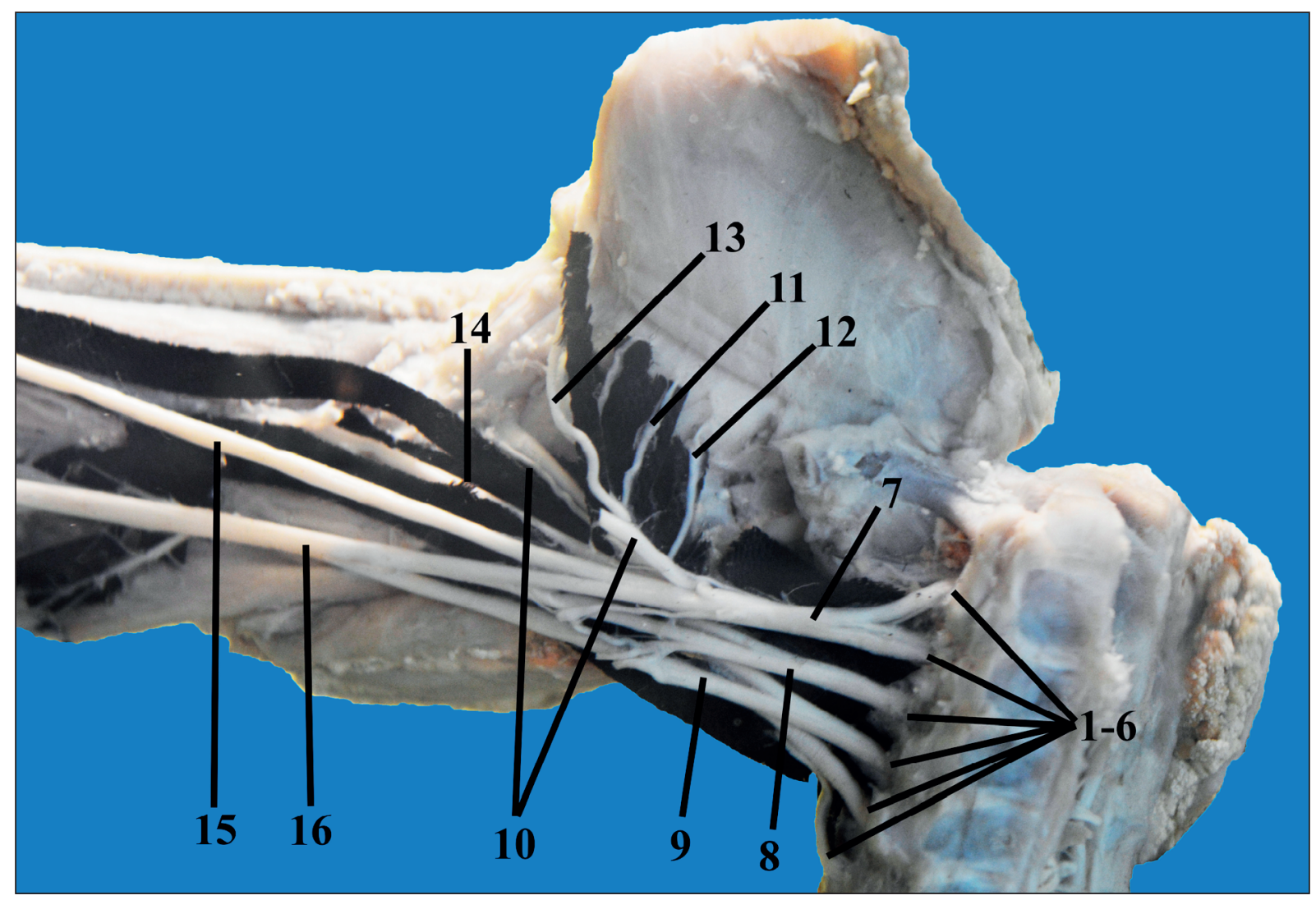

Fig. 4. Nerves of the right upper limb of a fetus with $290.0 \mathrm{~mm}$ of CRL. Frontal view. Gross specimen.

1-6 - anterior branches V-VIII cervical and I thoracic cerebrospinal nerves; 7 - upper trunk; 8 - middle trunk; 9 - lower trunck; 10 - axillary nerve; 11 - dorsal nerve of the scapula; 12 - thoracodorsal nerve; 13 - subscapular nerve; 14 - radial nerve; 15 - musculo-cutaneous nerve; 16 - median nerve.

the branches of the posterior and anterior arteries, enveloping the humerus, the thoracoacromial artery, the transverse artery of the neck, the artery enveloping the scapula, which anastomose among themselves. In 3 cases, a thin branch from the deep brachial artery headed to the infraspinous and the teres major muscles.

The muscles of the shoulder girdle connect the scapula and collar bone with the bones of the body and the humerus, and are arranged in two layers: superficial and deep ones. The triangle shaped deltoid muscle located on top of the shoulder joint and whose apex faces the humerus, belongs to the superficial muscles of the shoulder girdle. The deep muscles of the shoulder girdle include the supra- and infraspinous muscles, the teres major and minor muscles, as well as the subscapular muscle. The teres major and subscapularis muscles are involved in the formation of the posterior wall of the axillary fossa, and the deep muscles of the shoulder girdle limit the triangular and quadrangular spaces in the posterior wall of the axillary fossa, through which the neurovascular structures pass. We found out the features of fetal nerve and vascular topography of the deltoid, axillary and scapular areas in human fetuses aged 4-10 months. Our study only covers a part of the issue on the shape and boundaries of the triangular and quadrangular spaces, the topography of the axillary, suprascapular and subscapular nerves, and arterial anastomoses of the above listed areas in human fetuses.

Despite the fact that the concept of a quadrangular space of the axillary fossa is fairly well established in both general and topographic anatomy, we concluded that in human fetuses the quadrangular space is a narrow axillary canal in which three permanent walls, anterior and posterior foramina can be distinguished. The fourth non-permanent wall of the axillary canal is the surgical neck of the humerus. It has been established that the division of the axillary nerve into secondary trunks mostly occurs before entering the canal or in the canal itself. In the canal the axillary nerve or its secondary trunks are closely adjacent to the free part of the shoulder joint capsule. The latter resembles a trapezoid. The triangular space located medially looks like an axillary fissure in the human fetuses.

As a result of the study, we obtained data confirming the opinion of most researchers that each 


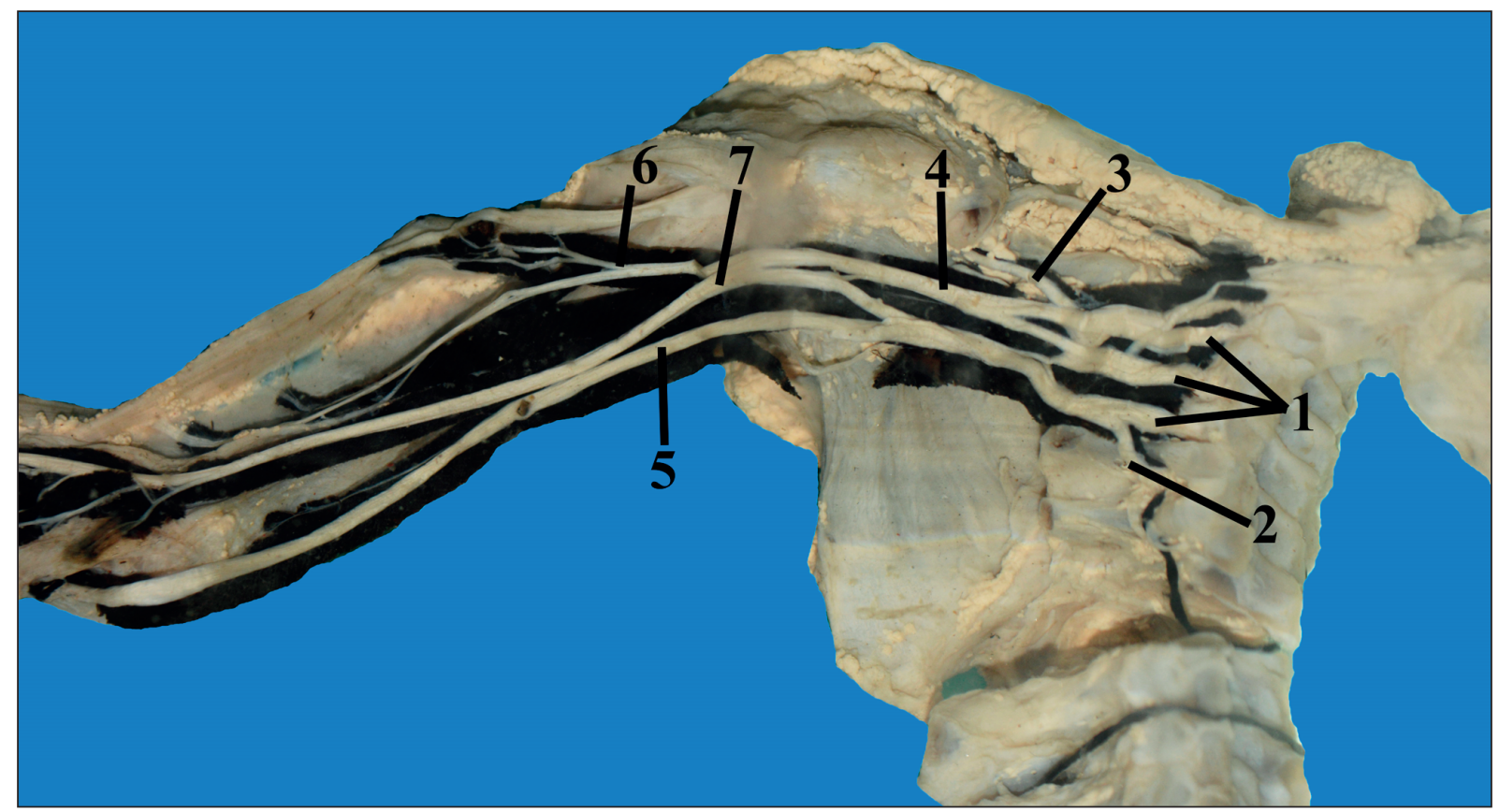

Fig. 5. Nerves of the right upper limb of a fetus with $350.0 \mathrm{~mm}$ of RCL. Frontal view. Gross specimen.

1 - upper, middle and lower trunks; 2 - subscapular nerve; 3 - axillary nerve; 4 -radial nerve; 5 - ulnar nerve; 6 - musculo-cutaneous nerve; 7 - median nerve.

source of blood supply and innervation gives several branches to a muscle ${ }^{23}$. It has been noted that the more a muscle or any of its parts are developed, the larger are the branches that feed this muscle or its part. The muscular hila are located not only on the inner surface of the muscles, but also on their outer surface. For example, the outer surface in the supraspinous muscle is less protected, but additional branches from the suprascapular artery enter here. The gates of the main artery in most cases are always located in the most protected places. The additional arteries, as well as the main arteries, in most cases have certain entry points into the muscles. They are usually located on the periphery. The topographic position of the artery hila for the muscles of the shoulder girdle is usually located within the middle third of the muscle belly. In rare cases, a branch from the brachial deep artery was involved in the blood supply to the infraspinous and the teres major muscle.

It has been established that the nature of the intramuscular distribution of vessels and nerves in each muscle of the shoulder girdle is peculiar and differs in the topography of the bundles of its muscle fibers ${ }^{24,25}$. If the direction of the vessels and muscle bundles does not match, a loose form of branching arteries (deltoid, supraspinous, teres minor and major muscles) is usually formed, and if it is consistent, it is mainly the trunk form (infraspinous and subscapular muscles). Intramuscular anastomoses are most numerous and have been found in all muscles. They were observed both among the arteries of the $1^{\text {st }}$, and the following orders, which is consistent with the data of some researchers ${ }^{22-24}$.

Therefore, our findings allow us to change the representation of fetal surgeons about the foramina in the posterior wall of the axillary fossa, the topography of the axillary nerve, and the arterial anastomoses in the area of the scapula. The features of the distribution of arterial anastomoses of the shoulder girdle muscles should be taken into account by plastic surgeons when cutting out full-fledged muscle flaps on the root. As a result of the study, information on the fetal topography of the arteries and nerves of the shoulder girdle muscles was clarified and supplemented.

\section{Conclusions}

1. In human fetuses, the triangular space located medially resembles the axillary fissure. The laterally arranged quadrangular space is a narrow axillary canal in which three permanent walls, anterior and posterior foramina can be distinguished.

2. Branching of the axillary nerve into secondary trunks for the most part occurs before entering the axillary canal or in the canal itself. In the canal the axillary nerve or its secondary trunks closely adheres to the free part of the shoulder joint capsule, which is trapezium-shaped. 
3. The axillary nerve is involved in the innervation of the posterior artery, enveloping the humerus and of its branches.

4. In all the muscles of the shoulder girdle extra-and intramuscular anastomoses between arteries of different orders and diameters were clearly seen. Intramuscular arterial anastomoses are most numerous and were found in all muscles.

5. In each muscle, there are both loose and a main type of branching of the arteries regardless of their shape. When the direction of the vessels and muscle bundles matches, the main form of branching (infraspinous and subscapular muscles) is usually formed, and in case of inconsistency, it is mainly loose (deltoid, supraspinous, teres minor and major muscles).

\section{Compliance with Ethics Requirements:}

"The authors declare no conflict of interest regarding this article"

"The authors declare that all the procedures and experiments of this study respect the ethical standards in the Helsinki Declaration of 1975, as revised in 2008(5), as well as the national law. Informed consent was obtained from all the patients involved in the study"

"No funding for this study"

\section{References}

1. Sakellariou VI, Badilas NK, Stavropoulos NA, et al. Treatment options for brachial plexus injuries. ISRN Orthopedic. 2014; 2014: Article ID 314137.

2. Smillie W. Collection of preternatural cases and observations in midwifery. London: Wilson \& Durham, 1764;3:504-507.

3. Laurent JP, Lee R, Shenaq S, Parke JT, Solis IS, Kowalik L. Neurosurgical correction of upper brachial plexus birth injuries. J Neurosurg. 1993;79(2):197-203.

4. Waters PM. Obstetric brachial plexus injuries: evaluation and management. J Am Acad Orthop Surg. 1997;5(4):205-214.

5. Hoeksma AF, Ter Steeg AM, Nelissen RG, van Ouwerkerk WJ, Lankhorst GJ, de Jong BA. Neurological recovery in obstetric brachial plexus injuries: an historical cohort study. Dev Mecd Child Neurol. 2004;46(2):76-83.

6. Foad SL, Mehlman CT, Ying J. The epidemiology of neonatal brachial plexus palsy in the United States. J Bone Joint Surg Am. 2008;90(6):1258-1264.

7. Chagas-Neto FA, Dalto VF, Crema MD, et al. Imaging assessment of glenohumeral dysplasia secondary to brachial plexus birth palsy. Radiol Bras. 2016;49(3):144-149.
8. Döderlein L. Principles of orthopedic treatment of flaccid paralysis. Orthopade. 2014;43(7):611-24.

9. Lindqvist PG, Erichs K, Molnar C, Gudmundsson S, Dahlin LB. Characteristics and outcome of brachial plexus birth palsy in neonates. Acta Paediatr. 2012;101(6):579-82.

10. Thatte MR, Babhulkar S, Hiremath A. Brachial plexus injury in adults: Diagnosis and surgical treatment strategies. Ann Indian Acad Neurol. 2013;16(1):26-33.

11. Van Gelein Vitringa VM, van Noort A, Ritt MJPF, van Royen BJ, van der Sluijs JA. Degree of contracture related to residual muscle shoulder strength in children with obstetric brachial plexus lesions. J Brachial Plex Peripher Nerve Inj. 2015;10(1):e23-e29.

12. Ferrante M, Wilbourn AJ. Electrodiagnostic approach to the patient with suspected brachial plexopathy. Neurologic Clinics. 2002;20(2):423-50.

13. Bhandari PS, Maurya S. Recent advances in the management of brachial plexus injuries. Indian J Plast Surg. 2014:47(2):191-198.

14. Naidoo N, Lazarus L, De Gama BZ, Satyapal KS. The variant course of the suprascapular artery. Folia Morphol (Warsz). 2014;73(2):206-9.

15. Kumar A, Goel S, Arora J, et al. Rare atypical vascular pattern of subscapular artery: Anatomico-clinical insight. Clin Ter. 2015;166 (3):118-20.

16. Aastha, Jain A, Kumar MS. An unusual variation of axillary artery: a case report. J Clin Diagn Res. 2015;9(1):AD05-7.

17. Bagoji IB, Hadimani GA, Bannur BM, Patil BG, Bharatha A. A unique branching pattern of the axillary artery: a case report. J Clin Diagn Res. 2013;7(12):2939-40.

18. Uysal I, Seker M, Karabulut AK, Büyükmumcu M, Ziylan T. Brachial plexus variations in human fetuses. Neurosurgery. 2003;53(3):676-84.

19. Kirik A, Mut SE, Daneyemez MK, Seçer HI. Anatomical variations of brachial plexus in fetal cadavers. Turk Neurosurg. 2017. doi: 10.5137/1019-5149.JTN.21339-17.2.

20. Natsis K, Papadopoulou AL, Paraskevas G, Totlis T, Tsikaras P. High origin of a superficial ulnar artery arising from the axillary artery: anatomy, embryology, clinical significance and a review of the literature. Folia Morphol (Warsz). 2006;65(4):400-5.

21. Olinger A, Benninger B. Branching patterns of the lateral thoracic, subscapular, and posterior circumflex humeral arteries and their relationship to the posterior cord of the brachial plexus. Clin Anat. 2010;23(4):407-12.

22. Chakravarthi KK, Siddaraju KS, Venumadhav N, Sharma A, Kumar N. Anatomical variations of brachial artery - its morphology, embryogenesis and clinical implications. J Clin Diagn Res 2014;8(12):AC17-20.

23. Kawashima T, Yoshitomi S, Sasaki H. Anatomical relationship between the superficial brachial arteries and the brachial plexus in humans, and their morphological significance. Folia Morphol (Warsz). 2004;63(4):465-71.

24. Beger B, Beger O, Koç T, et al. Quantitative and neurovascular anatomy of the growing gracilis muscle in the human fetuses. J Craniofac Surg. 2018;29(7):e686-e690.

25. Paraschiv B, Dediu G, Iancu A, Bratu O, Diaconu C. Superior vena cava syndrome - review. Arch Balk Med Union 2017;52(1):39-43. 